\title{
Theoretical Deoxyribonucleic Acid Homology Between Strains of Rhizobium japonicum ${ }^{l}$
}

\author{
GERALD H. ELKAN and RICHARD A. USANIS \\ Departments of Microbiology and Genetics, Institute of Biological Sciences, \\ North Carolina State University, Raleigh, North Carolina 27607
}

\begin{abstract}
Using a theoretical method, the highest possible per cent deoxyribonucleic acid homology between 26 isolates of Rhizobium japonicum was determined. The homologies between the isolates and a reference strain ranged from $69.5 \%$ to $95 \%$. Least significant difference analysis resulted in three statistically different but overlapping clusters. It was concluded on the basis of homology data that the species is a valid one, although one which shows considerable diversity.
\end{abstract}

The taxonomy of the genus Rhizobium Frank is based primarily upon symbiotic properties, and six species are presently recognized (1). Although some of the species of Rhizobium are restricted in their host range, $R$. japonicum can infect a number of legumes including some normally nodulated by other rhizobia. Because there is limited biochemical, nutritional, and physiological information available for $R$. japonicum, the validity of this species has been questioned. Determination of the deoxyribonucleic acid (DNA) base composition of 25 isolates of $R$. japonicum showed that 16 of the isolates differed significantly in base composition [expressed as mean molar percentages of guanine and cy tosine (\%GC); 4] .

Comparisons of the mean base composition of DNA expressed as \%GC have proven to be valuable taxonomic tools because of the wide range of variability of the DNA base composition of species of bacteria. The degree of genetic relatedness can then be estimated by establishing the per cent DNA homology between these microorganisms. The DNA homology between two organisms is that fraction of the total genome DNA having GC regions with common sequences. Ordinarily, the per cent DNA homology is determined experimentally by measuring hybridization between DNA from different organisms. However, a theoretical method for determining the highest possible degree of homology was recently reported by De Ley (2). This technique can be used to

1 Paper no. 3501 of the Journal Series of the North Carolina State University Agricultural Experiment Station, Raleigh, N. C. calculate the limits of DNA homology between sets of bacteria and depends upon the mean nucleotide composition, the molecular weight, and the distribution of bases in the chromosomal DNA. Homologies determined using this theoretical method compare well with those obtained by hybridization techniques.

Because of the wide range of $\mathrm{GC}$ ratios between 25 isolates of $R$. japonicum reported previously, it was questioned whether $R$. japonicum constituted one species (4). The data determined previously, therefore, are included here for the homology determination.

\section{MATERIALS AND METHODS}

Bacterial strains. The strains used in this study and their sources are given in Table 1.

Methods. Cultures were grown in 1-liter quantities of yeast extract mannitol medium (4) and incubated at $30 \mathrm{C}$ on a rotary shaker for 4 to 5 days. The cells were harvested by refrigerated centrifugation and washed three times in $0.15 \mathrm{M} \mathrm{NaCl}$ containing $0.1 \mathrm{M}$ ethylenediaminetetraacetic acid (EDTA) at $p \mathrm{H} 8$.

DNA isolations were prepared independently at least twice for each strain tested. A 2- to 4-g amount of the harvested cell paste was suspended in $25 \mathrm{ml}$ of saline-EDTA. Two milliliters of sodium lauryl sulfate $(25 \mathrm{~g} / 100 \mathrm{ml})$ were added, and the suspension was shaken vigorously in a water bath shaker at $60 \mathrm{C}$ for 15 to $20 \mathrm{~min}$. The released DNA was purified according to the procedure of Marmur (9). To determine the compositional \%GC distribution, the thermal denaturation temperature $\left(\mathrm{T}_{\mathrm{m}}\right)$ was converted to the \%GC by the equation of Marmur and Doty (10):

$$
\text { mole \%GC }=\left(\mathrm{T}_{\mathrm{m}}-69.3\right) / 0.41
$$

The thermal denaturation curves were obtained using a sample absorbance recorder (Gilford model 2000) 
TABLE 1. DNA base composition and theoretical DNA homology among 26 Rhizobium japonicum strains

\begin{tabular}{|c|c|c|c|}
\hline Strain no. & $\begin{array}{l}\text { Denaturation } \\
\text { temp (C) }\end{array}$ & Moles \%GC & $\begin{array}{c}\text { Highest possible } \\
\text { DNA homology with } \\
\text { R. japonicum } 258(\%)\end{array}$ \\
\hline $84^{a}$ & 94.50 & 61.47 & 77.2 \\
\hline $130^{a}$ & 94.52 & 61.52 & 70.6 \\
\hline $24^{a}$ & 94.52 & 61.52 & 70.6 \\
\hline $83^{a}$ & 94.53 & 61.53 & 70.9 \\
\hline $5563^{b}$ & 94.54 & 61.57 & 69.5 \\
\hline $508^{c}$ & 94.67 & 61.89 & 74.7 \\
\hline $6^{a}$ & 94.76 & 62.08 & 76.7 \\
\hline $31^{a}$ & 94.77 & 62.13 & 77.3 \\
\hline$W-9^{b}$ & 94.78 & 62.16 & 77.7 \\
\hline $29^{a}$ & 94.80 & 62.20 & 78.2 \\
\hline $5633^{b}$ & 94.89 & 62.41 & 80.6 \\
\hline $120^{a}$ & 94.92 & 62.50 & 81.6 \\
\hline $40^{a}$ & 94.95 & 62.56 & 82.2 \\
\hline g280-1 $b$ & 94.95 & 62.56 & 82.2 \\
\hline $46^{a}$ & 94.95 & 62.56 & 82.4 \\
\hline $62^{a}$ & 94.99 & 62.65 & 83.5 \\
\hline $125^{a}$ & 95.03 & 62.76 & 84.5 \\
\hline $122^{a}$ & 95.04 & 62.78 & 81.6 \\
\hline $10324^{d}$ & 95.09 & 62.91 & 85.4 \\
\hline $94^{a}$ & 95.15 & 63.05 & 87.8 \\
\hline W-1 $8^{b}$ & 95.17 & 63.09 & 88.4 \\
\hline $85^{a}$ & 95.19 & 63.13 & 88.8 \\
\hline $44^{a}$ & 95.22 & 63.21 & 89.8 \\
\hline $505^{c}$ & 95.28 & 63.37 & 91.6 \\
\hline g209-8 $b$ & 95.41 & 63.67 & 95.0 \\
\hline $258^{b}$ & 95.58 & 64.09 & 100.0 \\
\hline
\end{tabular}

${ }^{a}$ Obtained from Dean Weber, U. S. Department of Agriculture, Beltsville, Md.

${ }^{b}$ Obtained from A. A. Hendrickson, W. R. Grace Co., Princeton, Ill.

$c$ Obtained from $O$. N. Allen, Department of Bacteriology, University of Wisconsin, Madison, Wisc.

$d$ Obtained from American Type Culture Collection, Rockville, Md.

$e$ Mean molar percentage of guanine and cytosine.

attached to a monochrometer (Beckman model DU). When these distributions are obtained for each of two taxa, they can be used to assess the maximal possible amount of DNA homology between the taxa as measured by the amount of overlapping of the two distributions. This is essentially the method of De Ley (2) and is adapted here to determine the degree of relatedness between strains of $R$. japonicum.

The $\mathrm{T}_{\mathrm{m}}$ and the mole mean $\% \mathrm{GC}(\% \overline{\mathrm{GC}})$ for the 26 strains of $R$. japonicum are reported in Table 1 . The $\% \overline{\mathrm{GC}}$ is calculated from the above equation using $\mathrm{T}_{\mathrm{m}}$ for the value of T. Because the DNA of the different strains is of equal molecular weight, the area under the compositional curves is the same. The amount of overlap was determined by using the error integral, because the thermal denaturation curve can be considered as the error function of the \%GC distribution. Use of this function for comparing two strains requires the standard deviation of the strains sampled and the difference between the $\% \overline{\mathrm{GC}}$ of the two strains. The standard deviation is a measure of the range of the \%GC compositional distribution of the species.

Calculation of the species standard deviation is complicated by the asymmetry of the \%GC distribution, which is most likely associated with the existence of an excessive number of adenine-thymine-rich regions (2). However, the distribution appears to be approximately normal, and an approximate standard deviation, based on normal distribution theory, can be calculated. De Ley found (2), in addition, that each half of the distribution below and above $T_{m}$ is almost perfectly normal, although each has a separate standard deviation, $\sigma_{1}$ and $\sigma_{\mathrm{r}}$. In the study, these observations also appeared correct, with the left or lower side of the distribution always being broadest, thus necessitating that the standard deviations for the two halves 
be calculated separately and averaged to obtain a reasonable approximation to the species standard deviation under the assumption that the underlying distribution is normal.

In this experiment, two replicates of each of the 26 strains were measured. To determine the standard deviation for each half of the distribution, the \%GC's around $\% \overline{G C}$ were calculated for each replicate. Sums of squares for each half of the distribution were obtained and adjusted for the variation in replicates and strains. The resulting error sum of squares was used to determine the standard deviation, giving a standard deviation of $\sigma_{1}=5.49$ and $\sigma_{\mathrm{r}}=2.85$. The average standard deviation is 4.17 , and the corrected average standard deviation, $\sigma_{c}=\sigma_{u}-.75$, is 3.42 for the strains studied. To calculate the per cent homology, the complement error integral was evaluated over the range of zero to $\triangle \mathrm{GC}$ (when $\triangle \mathrm{GC}$ is the $\% \overline{\mathrm{GC}}$ for strain 258 minus the \%GC for the strain under consideration) and multiplied by 100. De Ley (2) gave the details of this procedure.

\section{RESULTS AND DISCUSSION}

Strain 258 was chosen as the reference strain because its isolated DNA had the highest $T_{m}$ of any of the strains. The degrees of homology between this reference strain and the other 25 strains are summarized in Table 1. The homologies ranged from 69.5 to $95.0 \%$. These homology data were plotted against $\mathrm{T}_{\mathrm{m}}$ or \%GC as shown in Fig. 1. Least significant difference analysis of the homology percentages resulted in three statistically significant but overlapping clusters. However, the degree of homology between some of the strains $(24,130,83$, 5563 ) and strain 258 is only about $70 \%$. Since Heberlein, De Ley, and Tijtgat (8) concluded that authentic strains of the same species

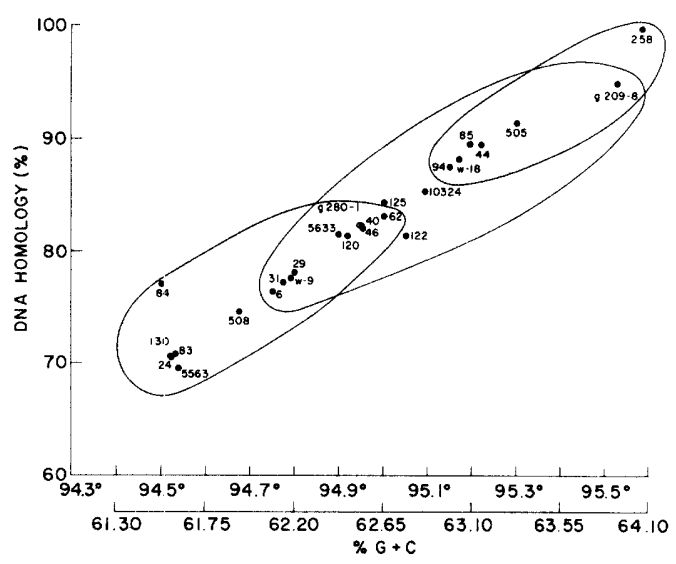

FIG. 1. Relatedness within the species Rhizobium japonicum on the basis of the highest possible theoretical DNA homology between 26 strains relative to $R$. japonicum strain 258 (DNA homology $=100 \%)$. should display at least $70 \%$ DNA homology based on their method of analyzing base composition data, we can say this species shows rather broad genetic diversity. Despite the questionable diversity of this species, $R$. japonicum strains exhibit closer affinity to each other than is shown between $R$. japonicum and other members of the family Rhizobiaceae. Thus, if one accepts the limit of 70\% homology within a species, this species appears to be a valid one based on DNA homology data although it exhibits just about the limits of diversity. These conclusions are supported by nutritional, serological, and physiological studies being conducted in our laboratory ( 5 , 6). In all of these studies, considerable diversity is observed, and yet the organisms appear more closely related to other isolates of $R$. japonicum than to other rhizobia.

Recently, some investigations on numerical taxonomy of the genus Rhizobium have suggested that $R$. japonicum and other slow growing species are so different from the other rhizobia as to warrant a separate genus for $R$. japonicum and related species $(7,11)$. One of these studies included six isolates of $R$. japonicum (7), whereas the other included only one representative of this species (11). DNA base homology studies of the taxonomy of the genus Rhizobium $(3,8)$ also included only a limited number of $R$. japonicum strains. In view of the genetic diversity of this species as found in the present study, a large sampling of representative strains of $R$. japonicum must be included in any valid taxonomic studies of this species or in establishing the status of the genus Rhizobium.

\section{ACKNOWLEDGMENTS}

This study was supported by grant GB-4378X from the National Science Foundation, Public Health Service research grant AI-107247 from the National Institute of Allergy and Infectious Diseases, and by U.S. Department of Agriculture, CSRS grant 916-15-04.

\section{LITERATURE CITED}

1. Breed, R. S., E. G. D. Murray, and N. R. Smith. 1957. Bergey's manual of determinative bacteriology, 7th ed. The Williams \& Wilkins Co., Baltimore.

2. De Ley, J. 1969. Compositional nucleotide distribution and the theoretical prediction of hómology in bacterial DNA. J. Theor. Biol. 22:89-116.

3. De Ley, J., and A. Rassel. 1965. DNA base composition, flagellation and taxonomy of the genus Rhizobium. J. Gen. Microbiol. 41:85-91. 
4. Elkan, G. H. 1969. Deoxyribonucleic acid base composition of isolates of Rhizobium japonicum. Can. J. Microbiol. 15:490-493.

5. Elkan, G. H. 1971. Biochemical and genetic aspects of the taxonomy of Rhizobium japonicum. In T. A. Lie and E. G. Mulder (ed.), Biological nitrogen fixation in natural and agricultural habitats. M. Nijhoff, The Hague, in press.

6. Elkan, G. H., and G. I. Kwik. 1968. The nitrogen, energy and vitamin requirements of Rhizobium japonicum. J. Appl. Bacteriol. 31:399-404.

7. Graham, P. H. 1964. The application of computer techniques to the taxonomy of the root-nodule bacteria of legumes. J. Gen. Microbiol. $35: 511-517$.
8. Heberlein, G. T., J. De Ley, and R. Tijtgat. 1967. Deoxyribonucleic acid homology and taxonomy of Agrobacterium, Rhizobium and Chromobacterium. J. Bacteriol. 94:116-124.

9. Marmur, J. 1961. A procedure for the isolation of deoxyribonucleic acid from microorganisms. J. Mol. Biol. 3:208-218.

10. Marmur, J., and P. Doty. 1962. Determination of the base composition of deoxyribonucleic acid from its thermal denaturation temperature. J. Mol. Biol. 4:109-118.

11. Moffett, M. L., and R. R. Colwell. 1968. Adansonian analysis of the Rhizobiaceae. J. Gen. Microbiol. 51:245-266. 